Anna-Giulia Brunello

Matthias Haenggi

Oliver Wigger

Francesca Porta

Jukka Takala

Stephan M. Jakob

\section{Usefulness of a clinical diagnosis of ICU-acquired paresis to predict outcome in patients with SIRS and acute respiratory failure}

Received: 26 August 2008

Accepted: 27 August 2009

Published online: 16 September 2009

(C) Copyright jointly hold by Springer and ESICM 2009

Electronic supplementary material

The online version of this article (doi:10.1007/s00134-009-1645-7) contains supplementary material, which is available to authorized users.

A.-G. Brunello · M. Haenggi · O. Wigger · F. Porta - J. Takala · S. M. Jakob (®) Department of Intensive Care Medicine, Inselspital, Bern University Hospital, University of Bern, 3010 Bern, Switzerland e-mail: stephan.jakob@insel.ch; jeannie.wurz@insel.ch

Tel.: +41-31-6321176

Fax: +41-31-6329644
Abstract Purpose: Neuromuscular abnormalities are common in ICU patients. We aimed to assess the incidence of clinically diagnosed ICU-acquired paresis (ICUAP) and its impact on outcome.

Methods: Forty-two patients with systemic inflammatory response syndrome on mechanical ventilation for $\geq 48 \mathrm{~h}$ were prospectively studied. Diagnosis of ICUAP was defined as symmetric limb muscle weakness in at least two muscle groups at ICU discharge without other explanation. The threshold Medical Research Council (MRC) Score was set at 35 (of 50) points. Activities in daily living were scored using the Barthel Index 28 and 180 days after ICU discharge. Results: Three patients died before sedation was stopped. ICUAP was diagnosed in 13 of the 39 patients (33\%). Multivariate regression analysis yielded five ICUAP-predicting variables $(P<0.05)$ : SAPS II at ICU admission, treatment with steroids, muscle relaxants or norepinephrine, and days with sepsis. Patients with ICUAP had lower admission SAPS II scores [37 \pm 13 vs. $49 \pm 15(P=0.018)$ ], lower Barthel Index at 28 days and lower survival at 180 days after ICU discharge (38 vs. $77 \%, P=0.033$ ) than patients without ICUAP. Daily TISS28 scores were similar but cumulative TISS-28 scores were higher in patients with ICUAP $(664 \pm 275)$ than in patients without ICUAP (417 $\pm 236 ; P=0.008)$. The only independent risk factor for death before day 180 was the presence of ICUAP. Conclusions: A clinical diagnosis of ICUAP was frequently established in this patient group. Despite lower SAPS II scores, these patients needed more resources and had high mortality and prolonged recovery periods after ICU discharge.

Keywords ICU-acquired paresis (ICUAP) - Systemic inflammatory response syndrome (SIRS) .

Multiorgan failure (MOF) . Mechanical ventilation · Prolonged weaning $\cdot$ Barthel Index

\section{Introduction}

Critical illness polyneuropathy (CIP) is an acute diffuse neuropathy resulting from axonal dysfunction in critically ill patients [1-4]. Since the first description by Bolton [1,4], further studies have documented the clinical, electrophysiological and morphological features [5-10]. Studies suggest that patients with suspected CIP may in fact have a myopathy as a contributing if not primary cause of the muscle weakness [11-13]. The diagnosis of both polyneuropathy and myopathy in the ICU has relied on electrophysiological or histological examinations. Consequently, the clinical equivalent of CIP is described as ICUacquired paresis (ICUAP) [14]. Nevertheless, the 
specificity of a clinical diagnosis of ICUAP has been confirmed using neurography and muscle biopsy [14]. In this seminal study, an association was found between clinical signs of muscle weakness and prolonged mechanical ventilation. Patients were included when on mechanical ventilation for 7 or more days and if awake. Similarly, a recently published study in patients on mechanical ventilation for 5 or more days found an association between ICUAP and length of mechanical ventilation, length of hospital stay and mortality [15]. However, a recent systematic review including data from almost 1,500 patients could not confirm an association between ICUAP and short-term mortality [16]. We aimed at extending existing data to cover both the early ICU phase and the consequences of clinically diagnosed ICUAP after the ICU stay.

The specific aims of this study were (1) to perform repeated clinical assessments for the presence of ICUAP starting as early as $48 \mathrm{~h}$ after ICU admission in mechanically ventilated patients with systemic inflammation, even if uncooperative, and (2) to evaluate resource use as estimated by TISS-28 scores and length of mechanical ventilation and ICU stay, functional integrity 6 months after ICU discharge, and severity of diseaseadjusted mortality when compared to patients without ICUAP. We hypothesized that a clinical diagnosis of ICUAP is associated with prolonged mechanical ventilation and ICU stay, increased resource use at ICU discharge, and delayed recovery, even when the diagnosis has not been confirmed with electrophysiological tests. This study was presented in part at the ESICM Congress in Berlin, Germany, in 2007 [17].

\section{Patients and methods}

This study was approved by the Ethics Committee of the Canton of Bern. The presumed will of the patients needed to be expressed by a close relative before study inclusion, and deferred written informed consent was obtained from patients. In addition, an independent physician confirmed inclusion and exclusion criteria. Between September 2005 and May 2006, all mechanically ventilated patients staying in the ICU for $48 \mathrm{~h}$ were screened for the presence or absence of $\geq 2$ systemic inflammatory response syndrome (SIRS) criteria [18]. Exclusion criteria are listed in the Electronic supplementary material (ESM).

Demographic variables and main diagnosis were recorded and Simplified Acute Physiological Score II (SAPS II) [19] was calculated at admission, and Sequential Organ Failure Assessment Score (SOFA) [20] was calculated at days 1, 3 and 7 after study inclusion and at ICU discharge. The therapeutic Intervention Scoring System (TISS-28) was recorded daily until ICU discharge as a surrogate for resource expenditure. The presence or absence of sepsis and/or SIRS was recorded on a daily basis. Protocols for cardiovascular management, sedation and weaning have been published previously [21]. Definition of sepsis, treatment of the patients and data recording are indicated in the ESM.

\section{Neurological examinations}

The Richmond Agitation/Sedation Scale (RASS) [22] was recorded every 2-4 h, and the Glasgow Coma Scale (GCS) [23] daily after stop of sedation, if performed. Neurological examinations were performed each day after sedation stop and included assessment of muscle strength of ten muscle groups (upper extremities: wrist flexion, forearm flexion, shoulder abduction; lower extremities: knee extension, hip flexion), as well as assessment of skin sensation (upper and lower extremities) and tendon reflexes (biceps, triceps, patellar and achilles). The presence of ICUAP was diagnosed according to the Medical Research Council (MRC) Score, whose inter-rater reliability has been confirmed [24]. Using this score, full muscle strength results in 5 points (M5) per tested muscle. A clinical diagnosis of ICUAP was made when weakness $(\leq \mathrm{M} 3)$ was diffuse, bilateral, involving upper and lower extremities, and resulted in a $>30 \%$ reduction in MRC score ( $<35$ points), independent of presence or absence of sensitivity disturbance or reduced tendon reflexes.

The clinical course of the patients was followed until hospital discharge. At day 28 after ICU discharge, all surviving patients were contacted (by phone call if discharged from hospital), and their fitness was assessed using the Barthel Index [25]. Six months after ICU discharge, the patients were invited to the clinic for an interview and a clinical neurological assessment.

\section{Statistics}

The detailed statistical approach is indicated in the ESM. Diagnosis of ICUAP required the presence of ICUAP criteria at ICU discharge. For the comparison between patients with and without clinical ICUAP, categorical variables were analyzed using the chi-square or the Fischer exact test, and quantitative data using the unpaired Student's $t$ test. Survival was described by Kaplan-Meier curves. Risk factors for ICUAP and for 180-day mortality were determined using multivariate regression analysis. Categorical data are presented as numbers (percentages), and quantitative data as mean $\pm \mathrm{SD}$. A $P$ value of $<0.05$ was considered significant.

\section{Results}

Between September 2005 and May 2006, 210 patients were screened, and 42 patients were included between 
day 3 and 13 after ICU admission (Fig. 1). Three patients were continuously sedated and died before a clinical evaluation of muscle strength was possible. Thirteen of the 39 evaluated patients $(33 \%)$ met the clinical criteria for ICUAP at ICU discharge.

\section{Demographics}

Demographic data are displayed in Table 1. The main ICU admission diagnoses were elective and emergency cardiac surgery and heart failure. SAPS II at ICU admission was lower in patients who developed clinical ICUAP $(37 \pm 13$ vs. $49 \pm 15, P=0.018)$. At study entrance ( $48 \mathrm{~h}$ after ICU admission), this difference disappeared $(52 \pm 13$ vs. $51 \pm 19, P=0.865)$.

Treatment of the patients

For detailed information, see ESM. Steroid, muscle relaxant and catecholamine treatment is indicated in Table 2. Insulin administration and glycemic control are reported in Table 2. There were no differences between patients with and without ICUAP.

SIRS, sepsis and multiple organ dysfunction

Days of SIRS and days of sepsis were significantly higher in patients with ICUAP $(10 \pm 5$ vs. $5 \pm 5, P=0.003$ and $2 \pm 3$ vs. $1 \pm 1, P=0.003$, respectively; Table 2$)$.

SOFA scores were similar in the two groups at day 1 ( $9 \pm 3$ vs. $9 \pm 2$ ). Multiple organ failure, defined as $\geq 2$ failing organs, was present in all but one patient without ICUAP at some time point during the ICU stay, but SOFA scores were higher on day 7 in patients with ICUAP $(9 \pm 3)$ when compared to patients without ICUAP $(6 \pm 3 ; P=0.043)$.

\section{Neurological findings}

GCS and RASS scores are indicated in Table 3. On the day of discharge from the ICU, 13 patients had a clinical diagnosis of ICUAP (33\%; Table 4). Detailed neurological findings are indicated in the ESM.

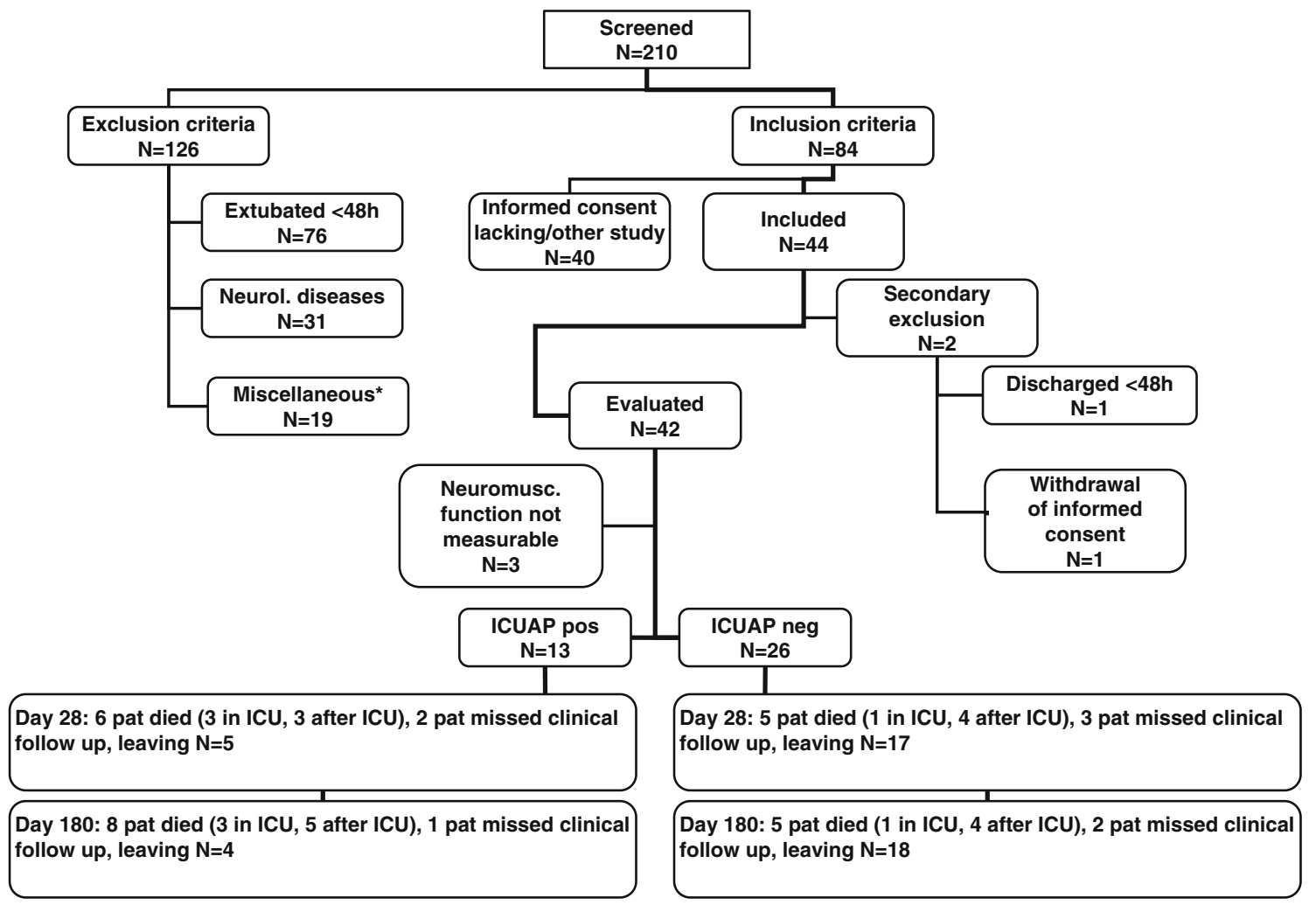

Fig. 1 Screened, included and excluded patients. $N=$ patients included or clinically examined. Miscellaneous exclusion criteria denoted by asterisks were: liver cirrhosis, human immunodeficiency virus infection, renal disease and peripheral arterial occlusion disease 
Table 1 Demographics, severity of illness and diagnoses in all patients, and in patients with and without a diagnosis of ICU-acquired paresis (ICUAP)

\begin{tabular}{|c|c|c|c|c|}
\hline & $\begin{array}{l}\text { All patients } \\
(n=39)\end{array}$ & $\begin{array}{l}\text { Patients with } \\
\text { ICUAP }(n=13)\end{array}$ & $\begin{array}{l}\text { Patients without } \\
\text { ICUAP }(n=26)\end{array}$ & $P$-value \\
\hline Age (years) & $67 \pm 14$ & $70 \pm 16$ & $65 \pm 13$ & 0.352 \\
\hline Male $[n(\%)]$ & $28(70)$ & $7(54)$ & $21(81)$ & 0.591 \\
\hline Female $[n(\%)]$ & $11(30)$ & $6(46)$ & $5(19)$ & 0.293 \\
\hline SAPS II & $45 \pm 15$ & $37 \pm 13$ & $49 \pm 14$ & 0.015 \\
\hline SOFA first day & $9 \pm 2$ & $9 \pm 3$ & $9 \pm 2$ & 1.000 \\
\hline TISS-28 at admission & $37 \pm 9$ & $37 \pm 11$ & $37 \pm 9$ & 0.619 \\
\hline Surgical diagnosis $[n(\%)]$ & $17(43)$ & $8(62)$ & $9(35)$ & 0.378 \\
\hline Major surgery $[n(\%)]$ & $7(18)$ & $3(23)$ & $4(15)$ & 0.681 \\
\hline Cardiac surgery $[n(\%)]$ & $10(26)$ & $5(38)$ & $5(19)$ & 0.465 \\
\hline Medical diagnosis $[n(\%)]$ & $20(51)$ & $5(38)$ & $15(58)$ & 0.565 \\
\hline Infections-sepsis [n (\%)] & 7 (18) & $2(15)$ & $5(19)$ & 1.000 \\
\hline Gastrointestinal [n (\%)] & $2(5)$ & $1(8)$ & $1(4)$ & 1.000 \\
\hline Cardiovascular $[n(\%)]$ & $9(23)$ & $1(8)$ & $8(31)$ & 0.25 \\
\hline Lung $[n(\%)]$ & $2(5)$ & $1(8)$ & $1(4)$ & 1.000 \\
\hline Trauma $[n(\%)]$ & $2(5)$ & 0 & $2(8)$ & 0.544 \\
\hline
\end{tabular}

Values are mean $\pm \mathrm{SD}$, numbers or percentages

Table 2 Exposures to drugs, glycemic control and days of SIRS and sepsis

\begin{tabular}{|c|c|c|c|c|}
\hline & $\begin{array}{l}\text { All patients } \\
(n=39)\end{array}$ & $\begin{array}{l}\text { Patients with } \\
\text { ICUAP }(n=13)\end{array}$ & $\begin{array}{l}\text { Patients without } \\
\text { ICUAP }(n=26)\end{array}$ & $P$-value \\
\hline Steroids $[n(\%)]$ & $4(10)$ & $4(31)$ & 0 & 0.009 \\
\hline Muscle relaxants $[n(\%)]$ & $10(26)$ & $7(54)$ & $3(11)$ & 0.008 \\
\hline Catecholamines $[n(\%)]$ & $28(72)$ & $13(100)$ & $15(58)$ & 0.007 \\
\hline Norepinephrine $[n(\%])$ & $17(44)$ & $10(77)$ & $7(27)$ & 0.005 \\
\hline Insulin, daily dose (U) & $24 \pm 22$ & $25 \pm 19$ & $23 \pm 24$ & n.s. \\
\hline Insulin, cumulative dose (U) & $411 \pm 381$ & $466 \pm 288$ & $377 \pm 433$ & n.s. \\
\hline Hypoglycemia $^{\mathrm{a}}(\%)$ & $2.9 \pm 2.9$ & $3.6 \pm 3.2$ & $2.5 \pm 2.7$ & n.s. \\
\hline Severe hypoglycemia ${ }^{\mathrm{b}}(\%)$ & $0.1 \pm 0.2$ & $0.1 \pm 0.3$ & $0.1 \pm 0.2$ & n.s. \\
\hline Hyperglycemia $^{c}(\%)$ & $24.0 \pm 12.6$ & $21.1 \pm 7.9$ & $24.6 \pm 14.4$ & n.s. \\
\hline Severe hyperglycemia $^{\mathrm{d}}(\%)$ & $4.5 \pm 4.9 \%$ & $3.8 \pm 2.5$ & $4.7 \pm 5.8$ & n.s. \\
\hline Days with SIRS & $7 \pm 5$ & $10 \pm 5$ & $5 \pm 5$ & 0.002 \\
\hline Sepsis $[n(\%)]$ & $17(44)$ & $8(61)$ & $9(35)$ & n.s. \\
\hline Days with sepsis & $1 \pm 2$ & $2 \pm 3$ & $1 \pm 1$ & 0.003 \\
\hline
\end{tabular}

Values are numbers, percentage or mean \pm SD. Total 3,845 glucose checks

a Hypoglycemia is defined as blood glucose $<4.5 \mathrm{mmol} / \mathrm{l}$

b Severe hypoglycemia is defined as blood glucose $<3 \mathrm{mmol} / \mathrm{l}$ c Hyperglycemia is defined as blood glucose $>7 \mathrm{mmol} / \mathrm{l}$

d Severe hyperglycemia is defined as blood glucose $>10 \mathrm{mmol} / \mathrm{l}$

\section{Mechanical ventilation, length of ICU stay and resource use}

Patients were ventilated for $9 \pm 6$ days and stayed in the ICU for $12 \pm 7$ days. Patients with clinical ICUAP remained significantly longer on mechanical ventilation and in the ICU (Fig. 2).

Neither TISS-28 scores at admission (Table 1), day 3 and day 7, nor mean daily TISS-28 scores (patients with ICUAP $40 \pm 4$, patients without ICUAP $42 \pm 10$; $P=0.477)$ differed between groups. The cumulative TISS-28 score was significantly higher in patients with
ICUAP $(664 \pm 275)$ than in patients without ICUAP $(417 \pm 236)(P=0.008)$.

Functional outcome and survival

The 180-day survival was significantly higher in patients without clinical ICUAP (77 vs. 38\%, respectively, $P=0.033 ; \chi^{2}$ test) (Fig. 3$)$.

The Barthel Index was lower in patients with ICUAP as compared to the other patients $(43 \pm 21$ vs. $81 \pm 24$; $P=0.011) \quad$ (Fig. 4). 180 days after discharge, the 
Table 3 Minimal and maximal GCS and RASS scores at day 1 and at discharge from the ICU

\begin{tabular}{|c|c|c|c|c|}
\hline Assessment & GCS-RASS & $\begin{array}{l}\text { All patients } \\
(n=39)\end{array}$ & $\begin{array}{l}\text { Patients with } \\
\text { ICUAP }(n=13)\end{array}$ & $\begin{array}{l}\text { Patients without } \\
\text { ICUAP }(n=26)\end{array}$ \\
\hline \multirow[t]{5}{*}{ Day 1} & GCS 15 & $11(28)$ & $6(46)$ & $5(19)$ \\
\hline & GCS $13-14$ & $16(41)$ & $6(46)$ & $10(38)$ \\
\hline & GCS $10-12$ & $6(15)$ & $1(8)$ & $5(19)$ \\
\hline & GCS 6-9 & $6(15)$ & 0 & $6(23)$ \\
\hline & GCS $<6$ & 0 & 0 & 0 \\
\hline \multirow[t]{5}{*}{ Discharge } & GCS 15 & $14(36)$ & $3(23)$ & $11(42)$ \\
\hline & GCS $13-14$ & $16(41)$ & $6(46)$ & $10(38)$ \\
\hline & GCS 10-12 & $5(13)$ & $3(23)$ & $2(8)$ \\
\hline & GCS 6-9 & $3(8)$ & $1(8)$ & $2(8)$ \\
\hline & GCS $<6$ & $1(2)$ & 0 & $1(4)$ \\
\hline \multicolumn{5}{|l|}{ Day 1} \\
\hline \multirow[t]{3}{*}{$\operatorname{Max}$} & RASS 0 to -1 & $8(21)$ & $3(23)$ & $5(19)$ \\
\hline & RASS $\geq 1$ & $21(54)$ & $4(31)$ & $17(65)$ \\
\hline & RASS $\leq-2$ & $10(26)$ & $6(46)$ & $4(15)$ \\
\hline \multirow{3}{*}{ Min } & RASS 0 to -1 & $3(8)$ & $1(8)$ & $2(8)$ \\
\hline & RASS $\geq 1$ & $1(2)$ & 0 & $1(4)$ \\
\hline & RASS $\leq-2$ & $35(88)$ & $12(92)$ & $23(88)$ \\
\hline \multicolumn{5}{|l|}{ Discharge } \\
\hline \multirow[t]{3}{*}{ Max } & RASS 0 to -1 & $21(54)$ & $5(38)$ & $16(61)$ \\
\hline & RASS $\geq 1$ & $17(43)$ & $8(61)$ & $9(35)$ \\
\hline & RASS $\leq-2$ & $1(2)$ & 0 & $1(4)$ \\
\hline \multirow[t]{3}{*}{ Min } & RASS $\overline{0}$ to -1 & $26(67)$ & $7(54)$ & $19(73)$ \\
\hline & RASS $\geq 1$ & $9(23)$ & 0 & 0 \\
\hline & RASS $\leq-2$ & $13(33)$ & $6(46)$ & 7 (27) \\
\hline
\end{tabular}

Values are numbers (\%). Due to the small numbers per group, statistical tests were not performed

Table 4 Neurological findings according to the Medical Research Council (MRC)

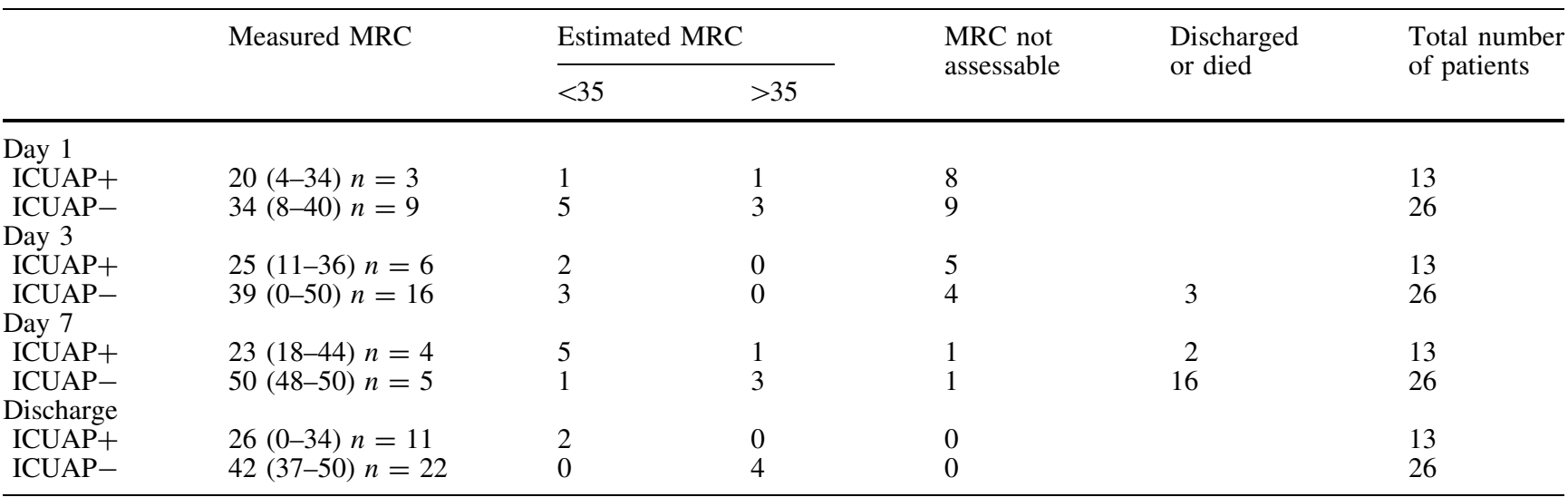

Values are median (range) and numbers

Barthel Index had improved in all patients. For details see ESM.

\section{Risk factors for ICUAP and death before day 180}

Based on the significant associations and clinical relevance of all results (see ESM), the following 11 variables were chosen for multivariate regression analysis with ICUAP as the dependent variable: SAPS II at ICU admission, SOFA subscore GCS on day 1, ICU LOS, days on mechanical ventilation, days with SIRS, days with sepsis, treatment with steroids, treatment with muscle relaxants, days with muscle relaxation, treatment with any catecholamine and treatment with norepinephrine. This yielded five ICUAP-predicting variables $(P<0.05)$ : SAPS II at ICU admission, steroid treatment, days with sepsis, treatment with muscle relaxants and norepinephrine treatment. The coefficients of the estimated regression model are presented in Table 5. The model statistics are presented in the ESM. Since ICU admission-SAPS II was unexpectedly lower in patients with ICUAP, the model was also tested without this variable. Here, the best predicting model consisted of the 


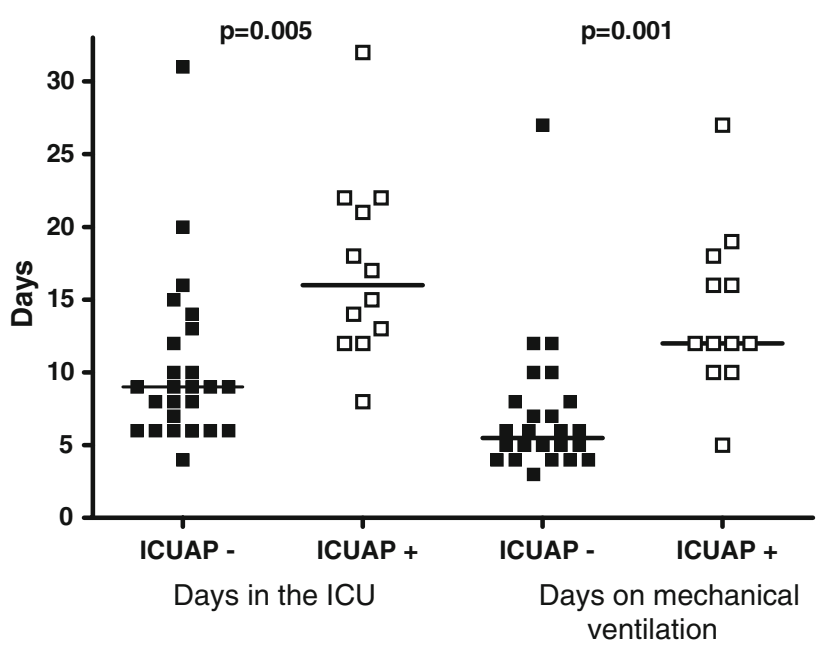

Fig. 2 Days in the ICU and on mechanical ventilation. ICUAP+ Patients with ICUAP, ICUAP - Patients without ICUAP. ICUAPpatients stayed $10 \pm 5.7$ days in the ICU (vs. $17 \pm 6.4$, $P=0.005)$. ICUAP - patients were ventilated for $7 \pm 4.7$ days (vs. $14 \pm 5.4$ days, $P=0.001$ )

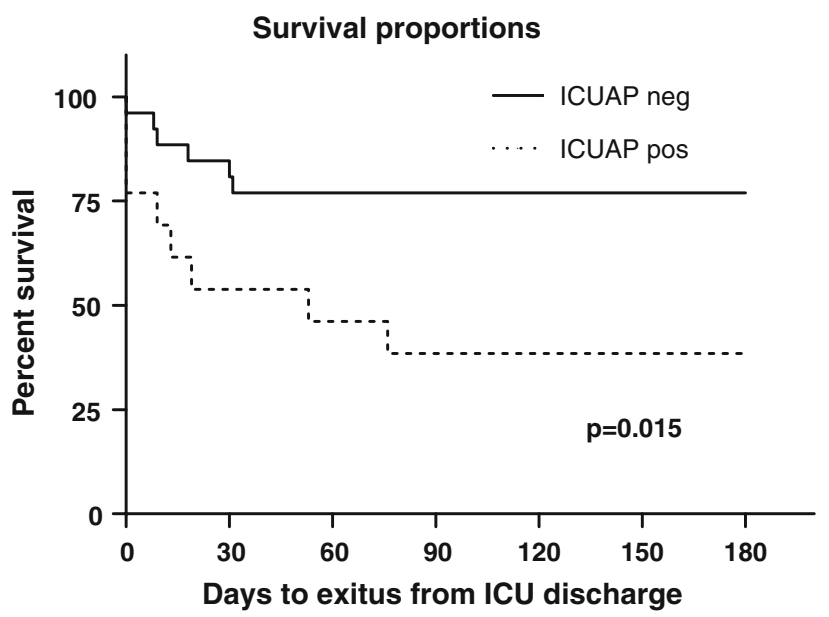

Fig. 3 Cumulative 28-day and 180-day post-ICU admission survival. ICUAP + Patients with ICUAP, ICUAP - patients without ICUAP. Statistics: Kaplan-Meier estimate

independent variables days with sepsis, steroid treatment and norepinephrine treatment only.

Using the same 11 variables and additionally ICUAP, with death before day 180 as the dependent variable, the only independent risk factor turned out to be the presence of ICUAP $(P=0.009$; for model summary and coefficients see ESM).

\section{Discussion}

The present study demonstrates that a simple clinical neurological assessment alone at ICU discharge is capable

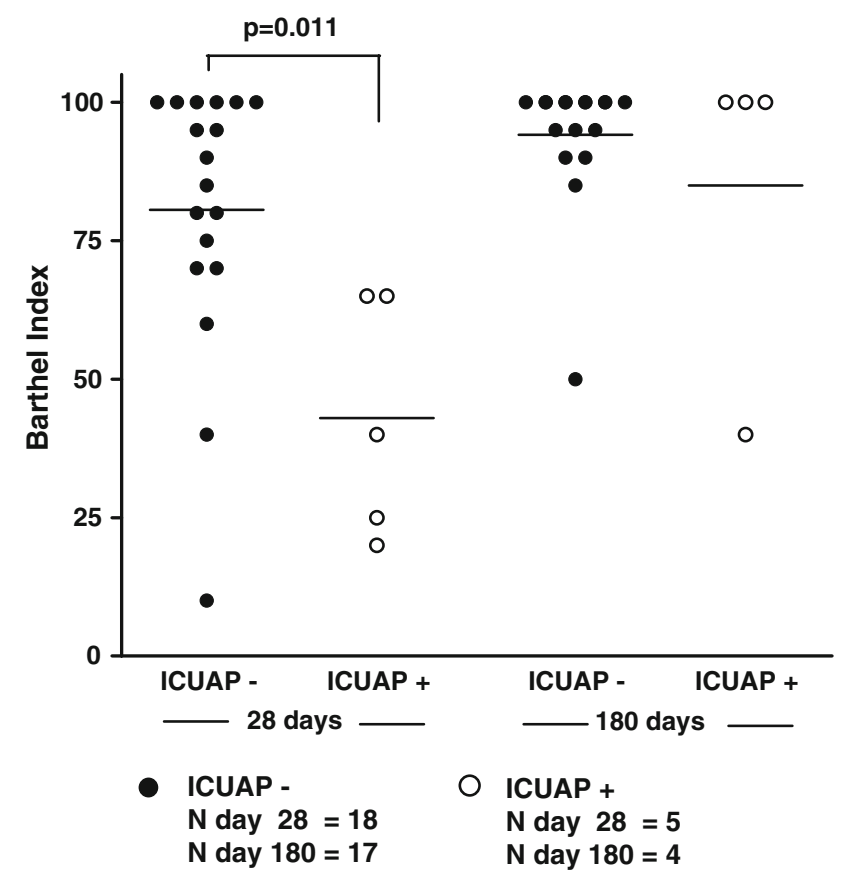

Fig. 4 Functional outcome [Barthel Index (range 0-100)]. Time in days after ICU discharge. ICUAP+ Patients with ICUAP, ICUAPpatients without ICUAP

of identifying patients at risk of high morbidity and mortality, and long-term sequelae for the quality of life. ICUAP is an incapacitating consequence of critical illness, and a major burden for the patients and the healthcare system. Although the number of patients is small, the resources needed for treatment are disproportionate: a conservative estimate based on our previous data on resource utilization of prolonged intensive care [26] suggests that at least $20 \%$ of all intensive care resources are used for the care of these patients. In the present study, cumulative TISS-28 scores were $50 \%$ higher in patients with ICUAP. This was not explained by more intensive treatment but by the increased length of stay, which in turn was a consequence of prolonged need for mechanical ventilation. Furthermore, ICUAP has longterm sequelae that impair the patients' quality of life long after ICU discharge.

Previous studies have indicated that the diagnosis of ICUAP can be made without such confirmatory tests as neuro- and myography with reasonable sensitivity [14, 15]. Both DeJonghe [14] and Ali [15] found an association between clinical signs of muscle weakness, including hand grip strength, and prolonged ICU length of stay, ventilator dependency and mortality. We found that on the day of discharge from the ICU, ICUAP was diagnosed in $33 \%$ of these patients.

Muscle weakness during clinical evaluation has been described in $25-30 \%$ of patients receiving intensive care after 4-7 days of mechanical ventilation $[14,27,28]$. 
Table 5 Coefficients and significances of the estimated regression with ICUAP as the dependent variable

\begin{tabular}{|c|c|c|c|c|c|}
\hline & \multicolumn{2}{|c|}{ Unstandardized coefficients } & \multirow{2}{*}{$\begin{array}{l}\text { Standardized coefficients } \\
\text { Beta }\end{array}$} & \multirow[t]{2}{*}{$t$} & \multirow[t]{2}{*}{ Sig. } \\
\hline & B & Std. error & & & \\
\hline SAPS II & -0.009 & 0.003 & -0.304 & -3.482 & 0.001 \\
\hline Treatment with steroids & 0.779 & 0.136 & 0.515 & 5.745 & 0.000 \\
\hline Days with sepsis & 0.104 & 0.027 & 0.395 & 3.901 & 0.000 \\
\hline Treatment with norepinephrine & 0.249 & 0.091 & 0.264 & 2.726 & 0.010 \\
\hline Treatment with muscle relaxation & 0.226 & 0.097 & 0.206 & 2.326 & 0.027 \\
\hline
\end{tabular}

Clinical assessment of muscle strength is inherently difficult in ICU patients due to sedation and the patient's frequent inability to fully cooperate. We therefore added an estimate of the muscle strength in patients unable to cooperate based on the strength and symmetry of their spontaneous movements during the sedation stop. Although less precise, this allowed estimation of the muscle strength earlier during intensive care. In contrast to other studies [14], in our study the number of patients in whom clinical assessment of muscle strength or a reasonable estimate thereof was never practicable was small (3 out of 42 ).

In most previous investigations, ICUAP was diagnosed by using electrophysiological tests [2, 29-33]. Whether clinical or electrophysiological testing is the preferred diagnostic method for ICUAP is a matter of discussion. We agree with the statement of Morris [34] that there are only a few reasonable indications for electrophysiological tests in patients with a diagnosis of ICUAP, mainly because of limited therapeutic options in the acute phase. Recent evidence suggests, on the other hand, that electrophysiological testing may help to predict the long-term prognosis by differentiating between patients with myopathy and neuropathy [35]. In view of the necessity for prolonged rehabilitation after ICU stay, any evaluation of patients for the presence of ICUAP seems mandatory. We suggest that bedside assessment of muscle strength can easily be done during the daily sedation stop to screen for signs of ICUAP.

Multivariate regression analysis showed that SAPS II at ICU admission, steroid treatment, days of sepsis, days on muscle relaxants and norepinephrine treatment, but not resource use (TISS-28) were associated with ICUAP in our patient cohort. The association between initial severity of illness and ICUAP is controversial. Our finding of lower admission SAPS II scores in patients with subsequent ICUAP was unexpected. This is probably related to case mix. The SAPS II score loses its predictive value for hospital outcome in patients requiring prolonged intensive care [36]. Furthermore, our sample included a relevant number of patients admitted after elective surgery, who were initially stable with low SAPS II scores, but whose stay in the ICU was prolonged due to complications developing later. It is therefore conceivable that with such a case mix the initial SAPS II scores have no association with the risk of prolonged ICU stay and development of ICUAP. Despite the high incidence of ICUAP, the etiological role of presumed risk factors is still unclear. In contrast to previous findings [14], female gender was not a risk factor for ICUAP in our rather small study.

Patients with ICUAP had a prolonged need for mechanical ventilation [31, 37-39]. It has been demonstrated that ICU-associated paresis is an independent predictor of prolonged weaning from mechanical ventilation [38]. In addition, both respiratory and limb muscle strength are altered after 1 week of mechanical ventilation [37]. However, there is still a lack of data regarding early, prospective evaluation of diaphragmatic and phrenic nerve functions in patients at risk of developing ICUAP.

There is no agreement in previous studies on mortality in patients with versus without critical illness polyneuropathy. Garnacho-Montero [31] reported ICU mortality of $20 \%$ in patients with ICUAP as compared to $10 \%$ in patients without (n.s.). In contrast, in the study by Leijten [32], the ICU mortality was $48 \%$ in patients with ICUAP versus $19 \%$ in patients without $(P=0.03)$. These discrepancies may suggest differences in case mix and diagnosis of ICUAP. In our study, clinical ICUAP was associated with decreased cumulative survival until 6 months after discharge from ICU. Most of the patients in both groups died at the hospital from the underlying illness within the first 28 days after discharge from the ICU.

In survivors with clinical ICUAP, the long-term functional outcome improved during the first 6 months after discharge from the ICU. This suggests the necessity and usefulness of referring such patients as early as possible to specialized rehabilitation facilities. For prognostic estimates, length of mechanical ventilation and ICU stay, and presence or absence of ICUAP may have an important impact in this group of patients.

A limitation of this study is the lack of confirmatory electrophysiological tests for ICUAP as a true gold standard. We did not systematically exclude specific diseases such as demyelinating polyneuropathy by lumbar puncture and neurophysiological assessments. However, rapid development of this disease in the ICU-without prior symptoms-is extremely unlikely. 
Furthermore, we used a simplified form of the MRC score with a reduced number of muscle groups to be tested, and the cutoff score for the clinical diagnosis of ICUAP was set arbitrarily at 35 . Therefore, the results are not directly comparable to those of others. However, there is no agreement in the literature on the correct cutoff score for the diagnosis of ICUAP. De Jonghe [37] described "limb weakness", and divided the MRC findings into thirds (0$28,29-46,47-60)$. Bednarik [40] defined quadriplegia or quadraparesis with MRC $<2$ as unequivocal clinical signs of ICUAP. Zifko [41] set the threshold at an MRC score $<3$ without indicating muscle groups. In an earlier study, De Jonghe [14] set the cutoff point at 48 of 60 points according to the standard MRC scale. We cannot exclude that more patients would have fulfilled criteria for ICUAP with a full clinical and neurophysiological examination. Also, by establishing a clinical diagnosis of ICUAP at ICU discharge only, we may have overlooked some cases with early, rapidly improving ICUAP. Furthermore, in a substantial number of patients, the MRC score was estimated rather than measured because not all patients were cooperative enough to allow a detailed and reproducible examination. At ICU discharge-when the definitive diagnosis of ICUAP was made-MRC had to be estimated in 6 out of 39 patients (15\%). This approach has not been validated and may have resulted in an under or overestimation of the incidence of ICUAP at a given time point. We do not believe that there is a better clinical estimate of muscle strength in uncooperative patients; nevertheless, our approach should be validated in further studies. A high number of patients with preexisting neurological illness (traumatic brain injury, intracerebral bleeding, subarachnoidal bleeding) and/or hemispheric processes were excluded and could not be assessed by a score that required movement on both sides. Finally, a substantial number of patients had to be excluded as a consequence of our inability to obtain informed consent. Whether the included patients represent the true ICU population with SIRS and mechanical ventilation $>48 \mathrm{~h}$ cannot be determined. Nevertheless, our approach resulted in a clearly definable patient group with an occurrence rate of ICUAP similar to other studies, high mortality after ICU discharge and a prolonged recovery period.

Another limitation is the lack of validation of the Barthel Index as a score for physical functional outcome in ICU survivors with acquired muscle weakness, and the lack of a systematic long-term assessment of cognitive outcome and quality of life. Further studies should address these issues and determine the effects of early specific rehabilitation in patients with clinical ICUAP.

We conclude that using clinical investigations at the bedside seems to be a simple way to identify a group of patients with increased mortality and protracted recovery of physical functions after ICU discharge. This may aid in recognizing patients in need of long-term rehabilitation. Accordingly, comprehensive electrophysiological evaluation of patients with ICUAP can be delayed until before discharge from the acute-care hospital for rehabilitation.

\section{References}

1. Bolton CF, Gilbert JJ, Hahn AF, Sibbald WJ (1984) Polyneuropathy in critically ill patients. J Neurol Neurosurg Psychiatry 47:1223-1231

2. Bolton CF (2005) Neuromuscular manifestations of critical illness. Muscle Nerve 32:140-163

3. Latronico N, Bertolini G, Guarneri B, Botteri M, Peli E, Andreoletti S, Bera P, Luciani D, Nardella A, Vittorielli E, Simini B, Candiani A (2007) Simplified electrophysiological evaluation of peripheral nerves in critically ill patients: the Italian multi-centre CRIMYNE study. Crit Care 11:R11

4. Bolton CF, Laverty DA, Brown JD, Witt NJ, Hahn AF, Sibbald WJ (1986) Critically ill polyneuropathy: electrophysiological studies and differentiation from Guillain-Barre syndrome. J Neurol Neurosurg Psychiatry 49:563-573

5. Lopez Messa JB, Garcia A (1990) Acute polyneuropathy in critically ill patients. Intensive Care Med 16:159162
6. Hund EF, Fogel W, Krieger D, DeGeorgia M, Hacke W (1996) Critical illness polyneuropathy: clinical findings and outcomes of a frequent cause of neuromuscular weaning failure. Crit Care Med 24:1328-1333

7. Coakley JH, Nagendran K, Yarwood GD, Honavar M, Hinds CJ (1998) Patterns of neurophysiological abnormality in prolonged critical illness. Intensive Care Med 24:801-807

8. Berek K, Margreiter J, Willeit J, Berek A, Schmutzhard E, Mutz NJ (1996) Polyneuropathies in critically ill patients: a prospective evaluation. Intensive Care Med 22:849-855

9. Maher J, Rutledge F, Remtulla H, Parkes A, Bernardi L, Bolton CF (1995) Neuromuscular disorders associated with failure to wean from the ventilator. Intensive Care Med 21:737-743

10. Zochodne DW, Bolton CF, Wells GA, Gilbert JJ, Hahn AF, Brown JD, Sibbald WA (1987) Critical illness polyneuropathy. A complication of sepsis and multiple organ failure. Brain 110(Pt 4):819-841
11. Latronico N (2003) Neuromuscular alterations in the critically ill patient: critical illness myopathy, critical illness neuropathy, or both? Intensive Care Med 29:1411-1413

12. Latronico N, Recupero D, Candiani A, Guarneri B, De Maria G, Antonini L, Fenzi F, Tomelleri G, Tonin P, Rizzuto N (1996) Critical illness myopathy and neuropathy. Lancet 347:1579-1582

13. Bednarik J, Lukas Z, Vondracek P (2003) Critical illness polyneuromyopathy: the electrophysiological components of a complex entity. Intensive Care Med 29:1505-1514

14. De Jonghe B, Sharshar T, Lefaucheur JP, Authier FJ, Durand-Zaleski I, Boussarsar M, Cerf C, Renaud E, Mesrati F, Carlet J, Raphael JC, Outin H, Bastuji-Garin S (2002) Paresis acquired in the intensive care unit: a prospective multicenter study. JAMA 288:2859-2867 
15. Ali NA, O'Brien JM Jr, Hoffmann SP, Phillips G, Garland A, Finley JC, Almoosa K, Hejal R, Wolf KM, Lemeshow S, Connors AF Jr, Marsh CB (2008) Acquired weakness, handgrip strength, and mortality in critically ill patients. Am J Respir Crit Care Med 178:261-268

16. Stevens RD, Dowdy DW, Michaels RK, Mendez-Tellez PA, Pronovost PJ, Needham DM (2007) Neuromuscular dysfunction acquired in critical illness: a systematic review. Intensive Care Med 33:1876-1891

17. Brunello A, Wigger O, Porta F, Ganter C, Haenggi M, Takala J, Jakob SM (2007) Long-term effects of a clinical diagnosis of critical illness polyneuromyopathy in patients with systemic inflammation. Intensive Care Med 33:S23

18. Bone RC, Balk RA, Cerra FB, Dellinger RP, Fein AM, Knaus WA, Schein RM, Sibbald WJ (1992) Definitions for sepsis and organ failure and guidelines for the use of innovative therapies in sepsis. The ACCP/SCCM Consensus Conference Committee. American College of Chest Physicians/ Society of Critical Care Medicine. Chest 101:1644-1655

19. Le Gall JR, Lemeshow S, Saulnier F (1993) A new Simplified Acute Physiology Score (SAPS II) based on a European/North American multicenter study. JAMA 270:2957-2963

20. Vincent JL, Moreno R, Takala J, Willatts S, de Mendonca A, Bruining H, Reinhart CK, Suter PM, Thijs LG (1996) The SOFA (Sepsis-related Organ Failure Assessment) score to describe organ dysfunction/failure. Intensive Care Med 22:707-710

21. Takala J, Dellinger RP, Koskinen K, St AA, Read M, Levy M, Jakob SM, Mello PV, Friolet R, Ruokonen E (2008) Development and simultaneous application of multiple care protocols in critical care: a multicenter feasibility study. Intensive Care Med 34:14011410

22. Sessler CN, Gosnell MS, Grap MJ, Brophy GM, O'Neal PV, Keane KA, Tesoro EP, Elswick RK (2002) The Richmond Agitation-Sedation Scale: validity and reliability in adult intensive care unit patients. Am J Respir Crit Care Med 166:1338-1344
23. Jennett B, Teasdale G, Braakman R, Minderhoud J, Knill-Jones R (1976) Predicting outcome in individual patients after severe head injury. Lancet 1:1031-1034

24. Kleyweg RP, van der Meche FG, Schmitz PI (1991) Interobserver agreement in the assessment of muscle strength and functional abilities in Guillain-Barre syndrome. Muscle Nerve 14:1103-1109

25. Mahoney FI, Barthel DW (1965) Functional evaluation: the Barthel Index. Md State Med J 14:61-65

26. Stricker K, Rothen HU, Takala J (2003) Resource use in the ICU: short- vs. long-term patients. Acta Anaesthesiol Scand 47:508-515

27. Zifko UA (2000) Long-term outcome of critical illness polyneuropathy. Muscle Nerve Suppl 9:S49-S52

28. de Letter MA, Schmitz PI, Visser LH, Verheul FA, Schellens RL, Op de Coul DA, van der Meche FG (2001) Risk factors for the development of polyneuropathy and myopathy in critically ill patients. Crit Care Med 29:2281-2286

29. Kane SL, Dasta JF (2002) Clinical outcomes of critical illness polyneuropathy. Pharmacotherapy 22:373-379

30. van Mook WN, Hulsewe-Evers RP (2002) Critical illness polyneuropathy. Curr Opin Crit Care 8:302-310

31. Garnacho-Montero J, Madrazo-Osuna J, Garcia-Garmendia JL, Ortiz-Leyba C, Jimenez-Jimenez FJ, Barrero-

Almodovar A, Garnacho-Montero MC, Moyano-Del-Estad MR (2001) Critical illness polyneuropathy: risk factors and clinical consequences. A cohort study in septic patients. Intensive Care Med 27:1288-1296

32. Leijten FS, Harinck-de Weerd JE, Poortvliet DC, De Weerd AW (1995) The role of polyneuropathy in motor convalescence after prolonged mechanical ventilation. JAMA 274:1221-1225

33. Tennila A, Salmi T, Pettila V, Roine RO, Varpula T, Takkunen O (2000) Early signs of critical illness polyneuropathy in ICU patients with systemic inflammatory response syndrome or sepsis. Intensive Care Med 26:1360-1363
34. Morris C, Trinder JT (2002) Electrophysiology adds little to clinical signs in critical illness polyneuropathy and myopathy. Crit Care Med 30:2612

35. Guarneri B, Bertolini G, Latronico N (2008) Long-term outcome in patients with critical illness myopathy or neuropathy: the Italian multicentre CRIMYNE study. J Neurol Neurosurg Psychiatry 79:838-841

36. Suistomaa M, Niskanen M, Kari A, Hynynen M, Takala J (2002) Customized prediction models based on APACHE II and SAPS II scores in patients with prolonged length of stay in the ICU. Intensive Care Med 28:479_ 485

37. De Jonghe B, Bastuji-Garin S, Durand MC, Malissin I, Rodrigues P, Cerf C, Outin H, Sharshar T (2007) Respiratory weakness is associated with limb weakness and delayed weaning in critical illness. Crit Care Med 35:20072015

38. De Jonghe B, Bastuji-Garin S, Sharshar T, Outin H, Brochard L (2004) Does ICU-acquired paresis lengthen weaning from mechanical ventilation? Intensive Care Med 30:1117-1121

39. Hermans G, Wilmer A, Meersseman W, Milants I, Wouters PJ, Bobbaers H, Bruyninckx F, Van den Berghe $G$ (2007) Impact of intensive insulin therapy on neuromuscular complications and ventilator dependency in the medical intensive care unit. Am J Respir Crit Care Med 175:480-489

40. Bednarik J, Vondracek P, Dusek L, Moravcova E, Cundrle I (2005) Risk factors for critical illness polyneuromyopathy. J Neurol 252:343351

41. Zifko UA, Zipko HT, Bolton CF (1998) Clinical and electrophysiological findings in critical illness polyneuropathy. J Neurol Sci 159:186193 